\title{
Individual Membership
}

All of the benefits below will begin January 1 and will conclude December 31 each year.

- Discounted ASA Annual Meeting registration fee

- Gratis print and digital subscription to African Studies Review (ASR) (to be requested by October 31 )

- Gratis digital subscription to History in Africa (HIA), an annual journal

- Discounted print subscription to History in Africa (add by May 15 at checkout for $+\$ 59)$

- Digital subscription to the ASA News biannual newsletter

- Access to the complete ASA News Archive via Cambridge University Press

- Access to the Annual Meeting Session Recording Archive

- Access to job postings and professional development opportunities

- Access to regular, Members-Only virtual events

- Listing in the ASA Specialist Directory (once profile is filled out)

- Listing in the ASA Online Membership Directory (personal contact info included for those opted in)

- Eligibility to win the ASA's Advocacy Travel Award

- Eligibility to vote in the Board of Directors elections (including the ESN Board Rep)

- Eligibility to serve on ASA Committees

- Eligibility to nominate individuals for the Distinguished Africanist Award and ASA Presidential Fellows

- Announcements via the ASA News

- Increased mentorship/mentee opportunities

Membership can be purchased securely online at https://myasa.africanstudies.org/

K-12 Teacher: $\$ 50$

Current Student: $\$ 50$

International Emerging Scholar*: \$5

Retiree: $\$ 100$

Annual Income - Below \$30,000: $\$ 75$

Annual Income - \$30,000-\$49,999: \$110

Annual Income - $\$ 50,000-\$ 74,999: \$ 170$

Annual Income - \$75,000-\$99,999: $\$ 190$

Annual Income - \$100,000-\$129,999: \$225

Annual Income - \$130,000-\$149,999: \$250

Annual Income - Above \$150,000: \$275

Sustaining Member**: $\$ 375$

Institutional: $\$ 2,500$

Lifetime: $\$ 3,500$

*The ASA defines an Emerging Scholar as in pursuit of one's terminal degree, or within five years post completion. International Emerging Scholars residing in the following countries are not eligible based on their designation as high income: United States, Australia, Austria, Belgium, Canada, Czech Republic, Denmark, Finland, France, Germany, Greece, Hungary, Iceland, Ireland, Israel, Italy, Japan, Korea, Luxembourg, Netherlands, New Zealand, Norway, Poland, Portugal, Slovak Republic, Slovenia, Spain, Sweden, Switzerland, and the United Kingdom.

**The ASA defines a Sustaining Member as a membership which includes a $\$ 150$ tax deductible donation within the membership fee for one year. As a thank you, the ASA offers a discounted registration and no onsite increase to Sustaining Members in their given membership year. 


\section{Cambridge Core}

For further information about the journal, please go to the publisher's journal Web site at cambridge.org/HIA 